\title{
LEVELS OF SELF-ESTEEM IN SOCIALLY MALADJUSTED UNDERAGE MALES - PRE AND POST THERAPY IN A CORRECTIVE INSTITUTION FOR JUVENILE OFFENDERS
}

\section{Justyna Siemionow, PhD}

University in Gdansk

\begin{abstract}
The text is a report on the research which was undertaken in a corrective institution for underage criminals. The starting point is one thesis: one of the sources of criminal activities is low self esteem and unsettled picture of yourself. The feelings of social rejection and lack of acceptance, hostile attitude to the world - they are closely related to self - esteem. The results of presented research shows that it can be changed as a result of therapeutic and educational programs.
\end{abstract}

Keywords: Juvenile delinquency, self - esteem, an effective juvenile rehabilitation model, cognitive -behavioral therapy, juvenile criminal's cognitive system, effectiveness of social rehabilitation process

\section{Introduction}

The Młodzieżowy Ośrodek Wychowawczy (MOW - Juvenile Education Centre) is a corrective institution for socially maladjusted minors between the ages of 12-18, which offers education and care, as well as therapy and the pursuit of personal interests. It is an open institution, meaning that a number of resident assignments are conducted outside the centre. Placing a minor in an MOW entails an educational measure which changes the individual's place of abode and frequently takes them out of their original environment. The aim is to separate the minor from their pathological family environment and /negative peer influence. At the beginning, minors placed in an MOW (on the basis of a Family Court decision) reject the opportunity for change residence and study in such a centre might offer. For this reason, they are provided with exceptional educational and psychological care in this difficult period of adaptation, with the staff taking all legal precautions to minimalise the risk of minors absconding. It is of paramount importance for the further rehabilitation process that a resident becomes aware of why he is in a centre, what future 
options finishing the school will offer, and simply that they are encouraged to want to be there and to have the motivation to change. This is of course an extremely difficult task which naturally does not always succeed, hence genuine instances of absconding from an MOW, after which the individuals involved are apprehended and brought back to the Centre. They have, however, been instances, where, after four weeks of absence as a result of flight, a resident is crossed off the register . Reasons for a resident being crossed off the MOW register:

1. change of educational measure employed

2. eight-week absence in the centre caused by the individual's flight

3. individual being placed in a penal institution or remanded in custody

4. reaching the age of 18 - when, having attained maturity, an individual must leave the Centre, with the court being able to extend the period until an individual finishes a given school year.

\section{Self -esteem as a factor in regulating the behavior of socially maladjusted.}

The main personality factors are; self-esteem, self-evaluation and self-acceptance. They are linked to each other. Self - esteem occurs together with various chronic inclinations and dispositions that in some cases constitute the personality structure. They can function as behavior regulations (Dymkowski 1995). In one of the first longitudinal study (Reckless; Dinitz; Kay 1957) comparing delinquent and non-deliquent boys , it was proven the relationship between a positive self-concept and crime. This theory posits that high self-esteem serves to protect one from future episodes of deviant behavior. So, we can say that low or lower self-esteem is one of the risk factors of the crime. A negative self-concept or self-esteem is conductive to the development of delinquent behavior. Behavior may be/ or is an expression of one's self concept. Hence, if a person has a low opinion of him/herself, this would likely be reflected ina wide array of negative behaviours that would include depression, alcohol abuse and criminality (Walters 1990 p.36-37).

\section{The main research questions:}

Research Question 1: What is the level of self-esteem of the residents? first and second study (comparison)

Research Question 2: How the level of self-esteem is correlated to the level of general aggression?

Research Question 3: Are the methods of treatment - in social rehabilitation process - effective?

Research Question 4: Is the cognitive - behavioral therapy an effective way of working with socially maladjusted? 


\section{Type and place of research}

The research in question assumes a division into control and study groups. The former was made up of pupils of post-secondary schools from the town of Malbork, the latter of residents of Juvenile Education Centre no. 1 in the same town. The study in both groups was conducted twice ( in the years 2011-2013) with the application of the same procedure and research tools 12 months apart. In the period between the first and the second assessment some of the residents of the MOW in Malbork underwent a course of individual cognitive and behavioural therapy. Moreover, while at the Centre, the individuals participated in a number of cultural and sports activities in which the educational aspect was always foregrounded. Additionally, the research conducted includes an overview of the MOW's function as a corrective institution and an attempt to answer the question if all the factors contributing to the "specific organisational culture" of this institution have any bearing on the effectiveness of the rehabilitation process. The study was conducted in only one centre in order to eliminate the effect of factors outside the researcher's control, such as interactions between pedagogical staff and residents. Moreover, with fifty-four such centres in Poland, each creates its own specific culture and atmosphere which cannot be overlooked as regards the effect they have on the effectiveness of the work conducted there, as each employs different rehabilitation methods and techniques.

\section{Table 1. The individual cognitive-behavioral therapy}

Researchers studying social competence have been interested not only in specific social skills but also in the types of social-cognitive processes that might underlie individuals' behavioral choices. A variety of theories propose that individual differences in social information processing skills may help explain why people confronted with the same social situation may choose to act in very different ways (Nangle,Hansen,Erdley, Norton;2010). To start working with a juvenile, we have to identify his distinct set of beliefs : concerning themselves, the world and their own future. This is the main task of the therapy. The second is - to exchange some of them into more socially adaptable.

29 boys from experimental group attended individual session which lasted 12 weeks. Each boy has two sessions a week ( 2x45 mnutes). The process of psychological changing was based on fundamental thesis of cognitive - behavioral therapy.

There are many arguments for using the cognitive - behavioral therapy in social rehabilitation process. Below are some of them: this kind of therapy doesn't take o lot of time, the rules are simple and clear for the 
patients, the patients can feel changes quite quickly. The outline of the therapy will be described in the further part of this article.

The number of participants in the study underwent a change in both groups, for the reasons mentioned earlier in the group of minors, whereas the group of pupils was reduced by 14 , with those missing having moved to other schools in the following school year. All boys who were at this time in the institution took part in this research, they agreed to be tested.

\section{Hypotheses:}

The research assumed the following hypotheses which were reviewed in the first and second study: (analyzed issue is so extensive that allowed the identification of the following hypotheses) Below, there are sixteen detailed hypotheses:

1. The level of self-esteem of the residents in the first study is related to the length of their stay in the Centre; the longer the stay, the higher the self-esteem level.

2. As to the various aspects of self-esteem: acceptance, goals, emotionality, efficiency, failure, opinion of others - there will be disparities between residents and pupils - in study I.

3. In the group of residents, the level of general aggression is higher than in the group of pupils. This concerns studies I and II.

4. The group of residents will display a lower level of general selfesteem in the first assessment in comparison to the level of general self-esteem in the group of pupils.

5. The level of the residents' general self-esteem on the first assessment will rise in comparison to the second assessment.

6. In the group of pupils, the level of general self-esteem on the first and second assessment will not change.

7. Residence in the Centre, i.e. the entirety of rehabilitation activities undertaken by the Centre, results in a positive change in the residents' behaviour e.g. no attempts to break out, better school results, no punishable acts committed, involvement in sports and cultural activities.

8. The level of the residents' general aggression on the first and second assessment will be higher than in the group of pupils.

9. The level of general aggression of the residents undergoing therapy will fall, in contrast to the individuals from the group not involved in therapy.

10. The level of general aggression in the group of pupils will remain steady i.e. there will be no significant differences between the first and second assessment. 
11. Substantial differences will surface between the group of pupils and the group of residents as to various forms of aggression tested with the Psychological Inventory of Aggression Syndrome.

12. The general indicator of residents' aggression measured posttherapy will be lower than pre-therapy.

13. The rise in the residents' self-esteem goes hand in hand with a fall in the general aggression indicator.

14. As the residents' self-esteem rises, there will be fewer instances of absconding and leaving the Juvenile Education Centre.

15. The group of residents undergoing therapy will display the anticipated changes in behaviour to a greater degree than the group of residents without therapy.

16. In the opinion of residents, positive changes in their behaviour will be perceptible to their wider family environment as much as to themselves.

\section{Research methods}

Both groups, experimental and control, underwent the same research procedure in the first and second assessments.

Particular stages of research, spread over a period of time, were the same in both studies.

\section{The following assessment tools were used: Self-esteem Questionnaire}

The questionnaire was constructed for the purpose (by the author of this article) of the study and standardised by testing a group of 500 individuals between 16-18 years old, i.e. corresponding with the target group. Out of 65 questions, independent arbiters selected 50, which in their opinion referred to self-esteem and changes relating to it. The 50 questions thus selected were included in the first version of the questionnaire and, after statistical analysis had been conducted, the 34 remaining questions formed the final version of the questionnaire. As a result of further statistical analysis (factor analysis) six factors were singled out:

1.Self-acceptance, 2. Goals and tasks to be completed, 3. Other's opinion, 4. Emotionality, 5. Failure, 6. Efficiency of action

\section{Table 2. The Psychological Inventory of Aggression Syndrome by Zbigniew B. Gaś}

The theoretical basis for the construction of the inventory was an understanding of aggression syndrome as informed and uninformed tendencies, directed inwards as well as outwards and manifested or merely latent. 
IPSA comprises 10 scales, of which each in turn contains several statements. These are rather short, clear and easily understood, which is important when it comes to the study of socially maladjusted minors, whose mental agility is not as acute as that of individuals in the mental norm.

EAS Temperament Survey - Buss \& Plomin

Polish adaptation by Włodzimierz Oniszczenko.

The questionnaire, which diagnoses temperament as a collection of inherited personality traits in the form of content categories, is selfdescriptive in nature, with the version for adults characterised by a simplicity of structure, clarity and a relatively small number of statements, important when it comes to conducting a study with centre residents.

The questionnaire comprises five scales: emotionality, fear, anger, activity and sociability.

During the course of the study, the changes in the behaviour of each resident were assessed twice. The assessment was carried out by the Permanent Team for the Assessment of the Resident's Condition made up of tutors, teachers, a psychologist, an education specialist and a social worker, i.e. people directly involved in working with minors. The assessment was carried out on the basis of the specially prepared behaviour assessment sheet, with the behaviour of each boy individually assessed as to various aspects of and the changes in the rehabilitation process specified. Fifteen statements, each on a five-point scale, allowed for the allocation of a specific number of points to reflect the general assessment of behaviour. The results, i.e. the first and second measurements, were compared against each other and could fall in a bracket of 15 (minimum value) to 75 points (maximum value).

Outline of the therapy towards modification of cognitive schemata regarding self-image and self-esteem for residents of Juvenile Education Centre no. 1 in Malbork.

The main aim of the therapy is a change in the perception of one's self, abilities and skills, as well as a perception of one's environment, and restructuring or creating new cognitive schemata concerning the 'self' to replace those most detrimental to the minors' behaviour as a whole. A change in the convictions concerning the 'self' is the key element in the therapy, and is based on the assumptions of cognitive therapy, including Beck's therapy assumptions (Kratochvil, 2003).

Many researchers attribute significant regulatory functions to the structure of the 'self', which are, on the one hand, very often reduced to the function of self-appraisal, and on the other, to the motivational- or behavioural-modifying function. The manifestation of the self-appraising function signals the emergence of evaluative opinions and emotions about 
one's self, and the motivating function - the emergence of the motivation to satisfy one's own needs.

In minors with certain malfunctions there exist so-called automatic thoughts, which appear very quickly, outpacing and giving rise to emotional states. Therefore, the ability to recount automatic thoughts leads to the understanding of emotional states and related malfunctions. Beck's research and observations prove that the content of automatic thoughts is very similar in persons who display certain malfunctions. For that reason, in minors diagnosed as socially maladjusted, a fixed group of such thoughts concerning their own selves can be singled out. These will constitute the starting point for individual therapy.

The change in the cognitive functioning of the individuals taking part in the therapy also encompasses the assumptions which lie at the basis of the atomatic thoughts i.e. cognitive schemata, dysfunctional conduct and the general rules for assessing one's own life and directing one's own actions. During therapy, answers are sought as to the reasons why automatic thoughts concerning the 'self' remain persistent. In co-operation with the patients, ways can be sought for assessing and valuing their own selves and their relations with others .

I presume that the dysfunctional assumptions will assume the structure of categorical statements constructed according to the zero-one rule. My experience so far shows that they will contain statements such as: everone, no-one, always, never etc. As in Beck's psychotherapy, I adopt the assumption that the cognitive schemata which lead to dysfunctional behaviour in minors may be modified if they become more accessible to the residents' consciousness. Furthermore, the change in cognitive schemata is also possible as a result of a change in a minor's ways of converting information and of work on habitual errors in thinking and perception. It is all the more important that the malfunctions in one's thinking should uphold what has been encoded in cognitive schemata and lead to a position whereby the patient's automatic thoughts are accompanied by the conviction that they are sure and steady.

Therefore, together with a resident I will be working on his ways of interpreting, drawing conclusions and merging particular fragments of knowledge about himself, as all this will boost his objectivity and result in a more accurate and realistic perception of his own self and the outside world, and will contribute towards the modification of cognitive schemata. The additional aim of the therapy is to teach the patient how to make proper use of the feedback received from third parties 


\section{Discussion of results}

At the beginning of a discussion of the results, reference needs to be made to the general research problem of the article in question, which concerns means of therapeutic action directed at socially maladjusted minors in order to raise the level of general self-awareness and, as a result, change the ways in which they perceive themselves, their abilities and the reality around them. This method of action will also lead to an improvement in the general functioning in the minors and, most importantly, working on their 'cognitive levels' is more likely, in the author's opinion, to lead to permanent changes in the boys' behavior. The results presented in the previous chapter additionally constitute an analysis of the indicators of effectiveness of the very process of rehabilitation, with the rather wide spectrum of these indicators allowing for a deep analysis of the actions undertaken and, by means of evaluation, for the selection of the most effective of these. It should be noted that an individual approach towards socially maladjusted minors should also be employed when it comes to assessing the effectiveness of a particular institution's actions. The effectiveness of the rehabilitation process may be analysed on two planes: internal and external. The former concentrates on the changes in the minors' behavior during their stay in the Juvenile Education Centre. The most important determinant of internal effectiveness is the number of attempts at absconding or leaving in a given period of time, which has been addressed in detail in the present article. External effectiveness relates to the functioning of the residents outside the centre, during holidays or leave, and after release, which is much harder to research as it requires the involvement of many institutions nationwide (with residents coming from all over Poland) but also indicates a possible area for future research.

Numerous studies confirm the thesis that the way we perceive ourselves defines our style of action. As literature the world over still devotes very little attention to the subject of transformations of the image of 'self' and the resulting change in behavior (Misiewicz 1999), such research initiatives are extremely valuable.

What poses a significant problem when conducting research among maladjusted individuals residing in Juvenile Education Centres or other institutions, even more isolated, is the size of the sample. With long-term studies, from one, two or three years in duration (if a change is to be observed), there emerges the problem of the dwindling number of individuals, for example, due to them leaving the centres as a result of having reached the age of eighteen. These persons may stay at their own request, which also constitutes a determinant of the effectivity of ongoing action, but they are not obliged to do so by court order, as in the case of minors. This aspect of the study of individuals undergoing rehabilitation, in 
its broadest sense, is described by H. Misiewicz (1999) who has conducted research in a group of drug addicts currently in an addiction treatment centre. In this case, the change in the number of samples available is beyond the researcher's control.

On establishing that one of the aims of the rehabilitation process employed in the MOW is a rise in residents' self-esteem, it has at the same time been assumed that the image of their own selves will undergo transformation. Presupposing, after J. Reykowski (1992), that the image of oneself plays an important part in the process of regulating behavior, it was expected that alongside a rise in residents' self-esteem, their general functioning will also improve, including a fall in the level of aggression.

\section{Conclusion from the research conducted}

1. residents and pupils differ as to the level of general self-esteem.

In view of the results obtained, one may categorically confirm the validity of the above statement. The considerations of social maladjustment have been widely described in the literature of the subject, therefore this work does not discuss the issue in detail.

In the course of a child's interaction with the environment, many experiences are gathered which form the basis for his or her social functioning. For the child, the environment mostly means the family environment provided by parents or guardians. For a small human, it is this first environment and the experiences which happen within it that have an impact on his or her entire life in the future. It is here where, apart from existential needs, the small child's mental needs are satisfied, including the need for safety, love, belonging, acceptance and appreciation.

Due to its stability of environment, the family offers the child support and provides mental equilibrium, which in turn creates appropriate conditions for the correct development of the child's personality. Should this equilibrium be disturbed for some reason, it exerts decisive impact on the child's development. In the case of socially maladjusted minors, it is family environments which display pathological traits, in particular: alcoholism in one or both parents, a family member's criminal record, multiple change of partners and family disintegration, as well as mental diseases or disorders in parents. Research concerning the reasons for social maladjustment points to the statistically significant relationship between family disintegration and the phenomenon in question. Given such conditions, it becomes impossible to fulfil parental obligations appropriately and to satisfy the child's needs, which has a definite influence on the development of the child's personality, resulting in a number of disorders, including the distabilisation of the self and a distorted self-image. Lack of positive reinforcement, distorted emotional ties or even rejection, all result in minors from such environments 
seeing themselves only in the negative aspect, as individuals who cannot do anything, have a lack of talent and are ugly or unwanted. All this shapes the socially maladjusted minors' self-esteem, a fact confirmed by the research conducted, in contrast to pupils who, assuming they come from so-called normal, undistorted families, display markedly higher self-esteem in comparison to their socially maladjusted peers.

2. residents will display a higher general aggression rate than pupils.

Analysis of results shows that the research hypotheses have been fully confirmed. Modern theories based on the results of empirical studies consider some forms of deviant behavior, including aggression, as a result of a long-term process, the beginning of which can be traced back to the early stages of development (Urban 2000).

The first measurement taken prior to therapy indicated a statistically significant difference in the level of general aggression in the groups of residents and pupils. This difference was also present after the second measurement and, despite the fact that the general aggression indicator was reduced in MOW residents, both in the groups undergoing therapy and those not, it was still higher than in the group of pupils. Residents' aggressive behavior is conditioned by a multitude of factors, some simply being acquired means of reacting to accumulated emotional tension or an answer to frustrating stimuli, which may in fact be neutral but may be perceived as threatening due to the distorted 'self', which results in violent reactions, often disproportionate to the initial signal which causes them.

3. there is a link between the level of general self-esteem and aggression rate in both residents and pupils.

As a way of assuming an attitude towards this statement, The SelfAssessment Questionnaire was prepared, standardised and adjusted to the cognitive abilities of the residents and adjusted to their deficits, with a view to eliminating the risk of misunderstanding of the questions or of causing tiredness. Too many questions directed at individuals with lower cognitive predisposition and unaccustomed to systematic intellectual activity may lead to a random selection of answers.

The functioning of individuals with lower self-esteem may be characterised as to the following mental symptoms: negative attitude towards self, hypersensitivity, anxiety, emotional tension, low motivation for action, feeling of worthlessness and lack of faith in one's abilities, and such social symptoms as: difficulty in forming interpersonal relations, multiple conflicts with the outside world and lack of trust towards others . Judging by the above descriptions, the relationship between self-esteem and general aggression level does not seem surprising. According to the author's predictions, the results of the research and the analysis conducted on the basis of it have confirmed the existence of such a relationship. A stable and 
positive image of the 'self', derived from self-esteem, is a basis for forging vital regulatory mechanisms (Reykowski 1992), which decide over adaptation to the prevailing social conditions.

4. residents and pupil groups differ as to particular aggression rates measured with the IPSA Questionnaire.

The studies conducted in the groups of residents and pupils (first and second measurements) point to the existence of differences between these groups as to aggression indicators measured with the IPSA Questionnaire. The differences are statistically significant, also when it comes to particular IPSA scales. The most parallel value in both groups is displayed by the scale concerning indirect aggression, not openly revealed. The data may be interpreted based on a number of elements. Firstly, the testees belong to the same age group, are under significant peer pressure and use the same technological advantages such as mobile phone or internet. Secondly, as teenagers they are very open to the influence of others and readily adopt the behaviour of third parties.

Moreover, all the individuals attend school and consequently function within the framework of certain conditions and rules set out by school regulations and are well aware of the fact that acts of irritation, anger or aggression will be met with instant punishment from the teaching staff. Therefore pupils tend to resort to communicating such information or signals under the guise of other kinds of behaviour. It should be stressed that among the pupils constituting the control group certain changes appeared on the second measurement which could possibly be linked to 'emotional development' and the stabilisation of emotions, with the 'self' and the pupils' own identity going through the process of formation. The changes mentioned concern the following IPSA scales: IV - unconscious aggressive tendencies, VI - indirect aggression. Some changes also occurred as to scale III - hostility towards the world around, the roots of which should be sought in the so-called adolescence crisis and a number of rebellious and oppositional behaviours towards the adult world.

At this point I would also like to mention the critical attitude of some researchers towards the method described. Despite the unquestionable usefulness of the IPSA Questionnaire, over several years some critical voices have come to the fore and led to the development of a revised version of this tool. Mutual relationships between the results in particular scales of both versions of the test were examined, and the correlation indicators between the IPSA scales and the IPSA II factors were measured. It emerged that in both cases there was high convergence of the factors tested. Hence, the application of both IPSA and IPSA II seems justified, as long as the limitations of the first version are considered, as in this case where analyses were conducted on raw scores without converting them to sten scores. 
5. the rise in self-esteem influences a shift in perception and quality of perception of he phenomena of the outside world.

In line with H. Markus' concept (1980), also considered in the present article, the schemata concerning the 'self' are cognitive and therefore function like other cognitive schemata (Oleś 2005). Therefore, all in-coming information is evaluated through the 'self', with the alleged marked preference for the information which verifies the self-schemata already in place (Pervin 2002), hence the tendency to distort the information about oneself. Low self-esteem is conducive to the absorption of negative information about oneself, which confirms the existent 'self' schema, but at the same time, such people are in desperate need of positive information about themselves. This in turn translates to unclear self-knowledge which renders an individual, and especially a young one, very susceptible to external influences. Lower self-esteem results in certain motivational deficits, with this kind of individual longing for praise, yet more willing to believe criticism. Overt caution, uncertainty, and fear of further failure paralyse the activity of those with lower self-esteem. For that reason, a rise in self-esteem, which in this work is treated as the function of self-image, will open the 'self' schemata to another, previously unperceived, information concerning one's own person as well as the surrounding world.

In the case of the residents who participated in the therapy with the aim of rebuilding their cognitive schemata concerning the 'self', a positive change in the 'outlook' was observed during the course of the present pedagogical work, which manifested itself through heightened activity in the local environment, participation in certain tasks alongside peers from external education institutions, improvement in interpersonal contacts and a more optimistic view of the future. The above observations are still in need of a research tool to collate them and create a starting point for further analysis but this may pose a scientific challenge for both the author of the article as well as for others with an interest in the issue.

6. residence and rehabilitation in the Juvenile Education Centre no. 1 in Malbork leads to positive changes in the behaviour of underage socially maladjusted boys

J. Reykowski's regulatory theory of personality (1992), quoted several times in this work, formulates personality as a system where the main aim is to exchange information with the outside world and to process it in order to obtain the information necessary for acting within the surrounding world. On arrival at the MOW, this most important 'system' created by the young persons' emergent personality is veering off in the wrong direction. Residence in the centre involves a number of phases, the first of which very important for the resident's further rehabilitation - is the phase of adaptation to the new situation. Considering the fact that the socially 
maladjusted minors are individuals with lower self-esteem, which does not encourage their facing up to new challenges or situations, this stage proceeds with a number of certain difficulties, a situation which calls for highly individualised rehabilitation, and most importantly - thorough diagnosis. As soon as the resident feels safe in the centre, naturally not in the sense of physical danger but emotionally, then the core stage of rehabilitation may begin. It might be worth mentioning that Juvenile Education Centre no. 1 in Malbork holds regular research on the feeling of safety, with special emphasis on newcomers. The positive changes in the residents' behaviour reveal themselves in a number of aspects: starting from hygienic habits, the culture of eating and clothing, so-called organic work, through to a marked rise in school results, completion of a certain study cycle and a choice of vocation, which allows the residents to find their place in today's difficult job market.

During the course of the school year every resident undergoes a detailed diagnosis twice, on the basis of which pedagogical staff develop individual rehabilitation plans or evaluate those already in place. What constitutes a significant indicator of the positive changes observed in the minors' behaviour is the negligible percentage (against the Centre's entire community) of punishable acts committed in the local environment while on holiday or on leave, despite the increasing frequency of such breaks with each new school year.

7. cognitive-behavioral therapy conducted with the residents individual sessions, allowing for each resident's resources and tailored to his needs and skills - results in a rise in general selfesteem.

In tandem with the emergence of a large range of social pathologies commenced the search for methods of reducing them. There were high hopes for scientific psychology and psychiatry, especially such trends as psychoanalysis and behaviourism, and in the last decades - cognitive psychology (Urban 2000). The theoretical model of the cognitive-behavioral therapy has been presented by many authors (f. ex: Beck 20110) Therefore here I will discuss only those aspects of the therapy which refer to socially maladjusted minors, with the main focus on the effects achieved or achieveable.

The main rule of the therapy in question is: thoughts, emotions, behaviours and physiological reactions are all elements of one system, with a change in any given part of this system resulting in changes in the remaining parts ( Curwen; Palmer; Ruddell 2006). Behavioural dysfunctions, at the heart of which lie emotional deficits, are closely linked to the negatively distorted view of the 'self' and the surrounding reality. The cognitivebehavioural therapy conducted with the residents concentrated, in line with 
the main premise of this trend, on two elements of thinking: automatic thoughts and the underlying convictions. The author of this work has devised a programme of such therapy for MOW residents, which was subsequently assessed by two experts - therapists who work with adolescents on a daily basis. Their opinions, albeit with a number of comments, were generally positive. The programme will undergo further evaluation and alteration, with the acknowledgment of the experience gathered so far.

A statistical analysis has confirmed the author's assumptions relating to the positive changes which emerge in the course of the therapy, indicating at the same time that the changes were significant and relatively stable in character.

The results obtained allow for the assumption that this therapeutic trend suitably fulfils its tasks as regards changes in the self-esteem of socially maladjusted minors. They are also closely linked, by working with cognitive resources to achieve a permanent restructuring in the 'self' schemata and a rise in self-esteem, with the behavioural correlate - i.e a change in behaviour. In the author's opinion, the behavioural trend itself, based on the strengthening or weakening of certain reactions, will only cause some 'local' changes i.e an improvement in behaviour during the stay in the MOW. The real effect of the rehabilitiation work, though, will be its permanence and reinforcement in the family environment or elsewhere, wherever the resident starts his adult life, without trespassing on established moral and legal boundaries.

8. in the group of pupils the level of self-esteem and the general aggression indicator will remain the same.

On the basis of the results obtained, the research hypotheses concerning the above issue can be fully confirmed. In the group of pupils who acted as a reference point for the analysis of the research problem of socially maladjusted individuals, the level of general self-esteem as well as the aggression indicator did not change during the course of the research. This does not mean, however, that these elements have reached a critical point and will not undergo any change. Self-esteem is a collection of convictions and opinions about oneself and is also described as the attitude towards oneself as a result of previous experiences (Hattie 1992). The period of adolescence is characterised by a great changeability and fluctuation of emotional states, at the root of which lies the inability to comprehend one's own feelings and reactions. It is a stage marked by the search for models, personal identity and place in life, hence the fluctuating self-esteem during this period, very often with just one event being able to cause a sharp drop or rise.

The group of pupils, whose average age was 17 years and 4 months, was characterised by a decidedly higher level of intellectual and emotional 
maturity than that of the residents. The time interval between the first and second study was 12 months. Undoubtedly, with time elapsing, changes occurred within the group, relating to the process of maturing and learning, but they were not significant enough to seriously affect the variables studied. This is totally in line with the author's expectations, set out according to the knowledge of human developmental psychology and the course of particular stages in life.

The main indicators of marked consistency in aggressive behaviour at any given period are particular tendencies in reactions, certain motivational systems and/or variations in organised cognitive-affective structures of the individual (Frączek, Zumkley, 1993), the role of which is highlighted by the present author. Of course, these personality variables cannot be considered as features which work independent of external conditions. The individual differences in aggressive behaviour and the permanence of this aggression depend on how external information is processed (Frączek; Zumkley 1993). Therefore in the group of pupils, whose correct level of socialisation may provide a basis for collision-free functioning within society, significant differences as to the aggression indicator did not surface, and for that reason one may conclude that the indicator remained the same.

By treating the 'self' schemata in the same manner as other cognitive schemata subject to the same laws, the positive image of oneself also determines the positive reception of outside phenomena, directs the selection of information and thereby regulates human behaviour and decides over the form any reaction will take. The currently increasing interest in methods of effective rehabilitation is not only related to the fact that today's youth are more difficult that in the past. Such a trend, a very uplifting one in my opinion, emerged as a result of an understanding of the importance of and necessity for this kind of action and that properly selected and applied actions will bring about measureable outcomes, observable on a national scale.

The intensive socio-economic transformations observable in Poland after 1990, and the sudden, albeit expected, opening of borders have to a large degree accelerated and intensified the demoralisation process and a large number of antisocial behaviours in minors, as well as adults, who then became models for their children.

\section{Conclusion and further research perspective}

The analysis of results in the context of the main subject of this work i.e the possibility of change in the self-esteem of socially maladjusted boys, and through this - a permanent improvement in their general functioning, allows for the formulation of some optimistic final conclusions and the specification of the conditions for an expected change to occur, both of 
which have been satisfied in the case of Juvenile Education Centre no. 1 in Malbork.

First, highly individualised work with the minors, based on a multidimensional diagnosis and analysis of the resident's family situation, second, active cooperation with parents, involving carers and home environments in the entire process of rehabilitation, opening up to the outside world and reaching out beyond the walls of the centre, third, selection of staff compatible with the needs of the institution, accounting for the predispositions and the so-called 'soft' skill competencies of the candidates, fourth, creating and implementing unique therapeutic programmes, in response to the residents' emotional and cognitive deficits, as well as evaluating and altering them in addition to testing their effectiveness on the basis of the most recent methods of statistical analysis.

\section{The most important is to bring the child to the institution as soon as possible, because the delay can increase the level of demoralization}

The theoretical assumptions and numerous practical solutions presented in this work indicate that there exists a multitude of rehabilitative actions, which are, crucially, becoming more and more tailored to the resident's personality type, while stressing the undeniable significance of a diagnosis formulated in an interdisciplinary manner. The present case study focuses solely on the psychological aspects of social maladjustment, yet does not omit the biological and genetic aspects of this phenomenon, which are also taken into consideration in such a diagnosis. The idea of 'diversified treatment', although a cornerstone of modern rehabilitation, does not boast too many empirically confirmed rules. The present work and the research conducted in connection with it constitute a step towards changing this situation. The crux of rehabilitation activity - as part of open rehabilitation is planning and implementation that activate the minors' potential (Konopczyński 2006). What is needed, therefore, is individual 'made to measure' methods of working with residents, which decidedly increase the effectiveness of the actions undertaken.

For centuries, with adults invariably being their next of kin, juvenile delinquency has constituted an integral part of adult criminality, and shaping and replicating these models served as the dominant method of education.

Ideas from many directions are currently emerging towards a solution to this problem, which, despite the passage of time, has lost none of its validity. Penal law is being stiffened and new institutions and centres are coming into being to nip juvenile delinquency in the bud. Very often, these are purely theoretical considerations, without the backing of theoreticians or experience with this type of youth. Therefore, to my mind there is a great need for further research and analysis into the already existing therapeutic 
programmes and rehabilitation activities, which should be considered in the context of a particular institution's entire course of activity.

Measurement of the therapy's effectiveness should take into consideration the perspective of all sides concerned with its outcome, i.e. the evaluations of the therapist, the patient, his relatives and the institutions which benefit from the potential effects of the treatment.

Cognitive-behavioural therapy programmes developed in rehabilitation institutions are systematically evaluated and supplemented with conclusions from other studies as well as observations and analyses of juvenile behaviour. More attention is being paid to the involvement of parents and carers who constitute an important group of programme beneficiaries. In fact, what is most important is the permanence of the resulting change in juvenile behaviour and its transplantation to another ground, the ground of independent adult life, as it is beyond doubt that such change does occur within the framework of the rehabilitation activities conducted in an MOW. Moreover, a growing number of Polish studies on how socially maladjusted minors live and think, as well as ways of correcting these, contribute to a rise in the effectiveness of the actions employed.

\section{References:}

Beck J., 2011, Cognitive Behavior Therapy: Basics and Beyond, second edition, New York: Published by Gilford Press.

Curwen B., Palmer S., Ruddel P., 2000, Brief Cognitive Behaviour Therapy, London: SAGE Publications Ltd.

Dymkowski M., 1995, Self - esteem as an inhibition to creative thinking, IN: Maruszewski T., Nosal Cz. (Eds), Creative information processing cognitive models, Poznań: A. Mickiewicz's University in Poznan, (p.139-147).

Frączek A., Zumkley H., 1996, Socialization and Aggression, Warszawa: Instytut Psychologii PAN, Wyższa Szkoła Pedagogiki Specjalnej im. Marii Grzegorzewskiej.

Hattie J. ,1992, Self concept, Hillsdale, New Jersey: Lawrence Erlbaum Associates.

Markus, H. (1980). The self in thought and memory, IN D. M. Wegner \& R. R. Vallacher (Eds.), The self in social psychology. Hillsdale, New Jersey: Erlbaum, (p. 102-130).

Nangle D.W., Hansen D.J., Erdley C.A., Norton P.J., (Eds.), 2010, Practiotioner's Guide to Empirically Based Measures of Social Skills, Softcover, ISBN 978-1-4419-0608-3.

Konopczyński M., 2006, The creative methods of social rehabilitation, Warszawa: PWN, Pedagogium.

Kratochvil S.,2003, The basics of psychotherapy, Poznań: Zysk i S-ka. 
Misiewicz H. ,1999, The structure of self-esteem in the process of rehabilitation of people addicted to drugs, Warszawa: WSPS.

Oleś P.K. ,2005, Introduction to personality psychology, Warszawa: „Scholar”.

Pervin L.A. ,2002, Psychology of personality, Gdansk: Gdańskie Wydawnictwo Psychologiczne.

Recless W.C., Dinitz S., Kay B., 1957, The self component in potential delinquency and potential non-deliquency, American Sociological Rewiev, 22,( p. 566-570).

Reykowski J.,1992, The emotional processes, motivation and personality, Warszawa: PWN.

Urban B.,2000, Disturbances in behaviour and youth crime, Kraków: Jagiellonian University.

Walters G.D, 1990, The criminal lifestyle. Patterns of Serious Criminal Conduct, Newbury Park, London, New Delhi: Sage Publications,.

Table 1: Framework of research

\begin{tabular}{|c|c|}
\hline \multicolumn{2}{|c|}{ Study I } \\
\hline experimental group & control group \\
\hline 87 people & 90 people \\
residents of MOW no. 1 & pupils of post-secondary schools \\
in Malbork & \\
\hline
\end{tabular}

\begin{tabular}{|c|c|}
\hline \multicolumn{2}{|c|}{ Study II } \\
\hline experimental group & control group \\
\hline 54 residents & 76 people \\
\hline $\begin{array}{c}29 \text { people } \\
\text { without therapy }\end{array}$ & pupils of post-secondary schools \\
\hline
\end{tabular}

Table 2: Results of the statistical analysis for particular factors in the scale.

\begin{tabular}{|c|c|}
\hline Factor & Cronbach's $\boldsymbol{\alpha}$ - for the entire scale \\
\hline SELF-ACCEPTANCE & $\mathbf{, 8 7 2 8}$ \\
\hline GOALS AND TASKS TO BE COMPLETED & $\mathbf{, 7 7 1 6}$ \\
\hline OTHERS' OPINION & $\mathbf{, 7 5 4 4}$ \\
\hline EMOTIONALITY & $\mathbf{, 7 4 0}$ \\
\hline FAILURE & $\mathbf{, 8 3 0 8}$ \\
\hline EFFICIENCY OF ACTION & $\mathbf{8 3 7 6}$ \\
\hline
\end{tabular}

source: author's own analysis 